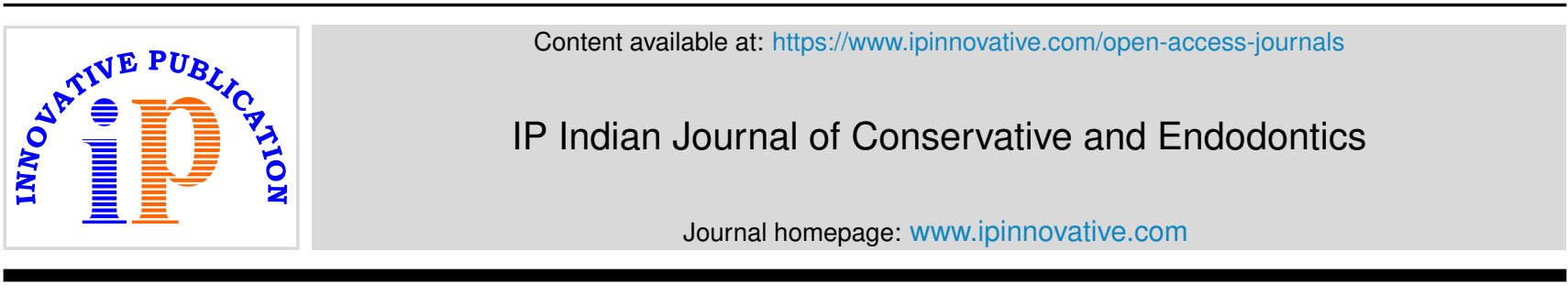

Original Research Article

\title{
Comparitive evaluation of antimicrobial efficacy of $0.1 \%$ octenidine dihydrochloride, $2 \%$ chlorhexidine and $2 \%$ chitosan against E.faecalis within the dentinal tubules
}

\author{
Akanksha Joon $^{1}$, Ambica Khetarpal ${ }^{1, *}$, Sanju Dahiya ${ }^{1}$ \\ ${ }^{1}$ Dept. of Conservative Dentistry and Endodontics, PDM Dental College \& Research Institute, Bahadurgarh, Haryana, India
}

\section{A R T I C L E I N F O}

Article history:

Received 23-10-2020

Accepted 03-11-2020

Available online 11-11-2020

Keywords:

Enterococcus faecalis

Antimicrobial

Octenidene Dihydrochloride

Chlorhexidene

Chitosan

\begin{abstract}
A B S T R A C T
Introduction : Root canal treatment is a type of endodontic therapy used to perform for the elimination of the micro-organisms by standardized mechanical instrumentation and adequate cleaning and shaping of the infected root canal. The readily available root canal irrigants which are used in endodontic therapy have shown somewhat toxic and harmful side effects when used at certain concentration, some of the endodontic irrigants have shown species specific resistance to a particular microbial load that's why there is a need to discover newer irrigants which are non toxic, effective and can be used safe to use.

Aim: In vitro evaluation and comparision of the antimicrobial efficacy of $0.1 \%$ octenidine dihydrochloride (OCT), of $2 \%$ chlorhexidene (CHX) and $2 \%$ chitosan as root canal irrigant against E. faecalis within the dentinal tubules at $200 \mu$ and $400 \mu \mathrm{m}$ depth.

Materials and Methods: Seventy two freshly extracted mandibular molars were decoronated and the mesial root specimen was standardized till working length. E.faecalis (strain MTCC 439) was grown on brain heart infusion sheep blood agar plate until seven days and the decoronated root specimens collected were divided into four groups $(\mathrm{n}=18)$ based on irrigation protocol: Group $1-2 \%$ chlorhexidene $(\mathrm{CHX})$, Group 2 - 0.1\% octenidine dihydrochloride (OCT), Group 3-2\% chitosan and Group 4 - normal saline . Each specimen was irrigated with particular irrigant till 3 minutes. Dentin shavings were obtained from root specimens using diamond disc and these dental chips were used to calculate the colony forming unit at $200 \mu$ and $400 \mu \mathrm{m}$ depth. The data obtained after the experiment was statistically analyzed.

Results: Non significant difference has been shown by group 1when compared with group 2 while significant difference has been shown by group 3 when compared with group 1 and group 2 by taking into account that group 4 is taken as control group. Significant difference was found when all the groups 1-4 were compared at 200 and $400 \mu \mathrm{m}$ depth.

Conclusion: It was observed and evaluated that antimicrobial efficacy of $2 \%$ chitosan against e. faecalis was found to be higher as compred to $2 \%$ chlorhexidene $(\mathrm{CHX})$ and $0.1 \%$ octenidine dihydrochloride (OCT) both at $200 \mu$ and $400 \mu \mathrm{m}$ depth.
\end{abstract}

(C) 2020 Published by Innovative Publication. This is an open access article under the CC BY-NC license (https://creativecommons.org/licenses/by-nc/4.0/)

\section{Introduction}

Elimination of microorganisms from the infected root canal pulpal space followed by three dimensional obturation is the primary goal of endodontic therapy. For the success of endodontic therapy one have to remove the debris /smear layer from the infected pulpal space and

\footnotetext{
* Corresponding author.

E-mail address: drambicakhetarpal@gmail.com (A. Khetarpal).
}

dentinal tubules, standarized mechanical instrumentation and adequate cleaning and shaping of the root canal passage has to be performed. This can be difficult to achieve due to the nature of the root canal anatomy which consists of isthmuses, fins, loops, deltas, anastomoses, and other irregularities within which microbes and debris get compacted. Conventional hand and rotary instrumentation fails to reach these areas. ${ }^{1,2}$ Thorough irrigation of root canal system has to be performed along with mechanical 
instrumentation for the removal of bacteria, debris, and the smear layer in the root canal system. ${ }^{3,4}$

Bacteria results in the development of pulpal disease, periapical pathosis and post-treatment disease after an endodontic therapy hence the complete eradication of microorganisms and their formed by-products from the root canal system is compulsory for the success of the this treatment. ${ }^{5}$ There are many significant pathogens which are present in root canal systems as the nature of infection is polymicrobial and E. faecalis is also one of them. Enterococcus faecalis, found in the root canal anatomy mainly in the re- treatment cases is a facultative anaerobic bacteria which is gram-positive, and mainly responsible for endodontic treatment failures and asymptomatic persistent infection. Once a root canal is invaded by Enterococcus faecalis, it forms a biofilm by adhering to root canal walls, and then keep on multiplying by forming communities which makes them 1000 times more resistant against antimicrobial agents, antibodies and phagocytosis than the isolated planktonic organisims. ${ }^{6-8}$

Microbes are present not only in the root canal passage system, but they are also found in fins, and anastomose and can be penetrate at varying depths of up to $300 \mu \mathrm{m}$ within the dentinal tubules. These microorganisms when reside within a supporting environment they can proliferate and again reinfect the root canal system. ${ }^{9}$ Therefore, priority should be given for the introduction of newer antimicrobial endodontic irrigant which can be used during root canal treatment.

Octenidine dihydrochloride is a type of bispyridine antimicrobial compound that carries 2 cationic active centers per molecule and had shown antimicrobial effects which are broad spectrum in nature and includes both gram-positive and gram-negative bacteria, fungi, and several viral species. ${ }^{10}$ It exerts bactericidal/fungicidal effects by interfering with cell walls and membranes. It is widely utilized in the medical field for skin burns and decontaminating mucous membranes and open wounds ${ }^{11}$ and is also utilized in mouthwash formulations and other dental applications. Reports had been shown that Octenidine dihydrochloride used in the form of mouthrinse can be beneficial to inhibit bacterial plaque accumulation and progression of dental caries both in rats $^{12}$ and humans. Octenidine dihydrochloride has shown relative non-cytotoxicity at the site of action ${ }^{13}$ and good antimicrobial activity.

Chlorhexidine Gluconate $(\mathrm{CH})$ is another widely used endodontic irrigant and medicament because of its wide selection of antimicrobial activity due to its cationic structure against Gram-positive and Gram-negative bacteria and yeasts also but there is no role of chlorhexidine in the dissolution of organic tissue. $\mathrm{CHX}$ features a unique property of substantivity against some resistant bacteria such as Enterococcus faecalis. ${ }^{14}$
Recently Chitosan, which is a natural polysaccharide and the deacetylated derivative of chitin, has gained popularity for its effective antibacterial and biodegradability. These are the foremost structural components of the cuticles of crustaceans, insects and molluscus and it's useful for various biological activities like antimicrobial activity, antitumour activity, haemostatic activity and acceleration of wound healing. Chitosan is a cationic biopolymer which is non toxic in nature with biocompatible, bioadhesion, and biodegradable properties. ${ }^{15,16}$

Hence, this study was undertaken evaluate and compare the antimicrobial efficacy of $0.1 \%$ octenidine dihydrochloride, $2 \%$ chlorhexidine and $2 \%$ chitosan against E.faecalis.

\section{Materials and Methods}

This in vitro study was conducted in department of conservative Dentistry and Endodontics, PDM dental college and research institute, Bahadurgarh, Haryana during the period from January 2020 to February.

In this study 72 intact freshly extracted Mandibular Permanent Molar teeth collected from Department of Oral and Maxillofacial Surgery, PDM Dental College \& Research Institute, Bahadurgarh, Haryana. The inclusion criteria includes teeth with straight roots (canal curvature less than 5 degrees) selected according to schneider's method. Teeth with curvature more than 5 degree, having evident caries, restoration or those who had immature apices were excluded. After extraction, soft tissue calculus were mechanically removed from these teeth and the specimens were immersed in $0.2 \%$ sodium azide solution until further use.

The samples selected were disinfected until 24 hours and stored in saline until the samples were used. Before instrumentation, soft tissue and calculus was removed mechanically from the root surface by a periodontal scaler. A diamond disc was used to decoronate the teeth specimens and then the specimens were prepared till working length. 25 K-file (Mani Inc, Tochigi, Japan) was used initially to prepare the root canal $0.5 \mathrm{~mm}$ beyond the apical foramen. ${ }^{17}$ Gates Glidden drills sizes \#3 to \#1 (Mani Inc, Tochigi, Japan) were used to prepare the coronal part of the canal and by the use manual technique the apical size was standardized to $50 \mathrm{~K}$-file. Gates Glidden drill \#2 with a slow speed handpiece was used to prepare the middle third of the canal and to standardize the internal diameter. ${ }^{18}$ The apex was sealed using light cure composite resin (Tetric $\mathrm{N}$-Cream, Ivoclar Vivadent AG, Liechtenstein) and root surface was coated with nail varnish. Glass test tube was used to place $3 \mathrm{ml}$ of brain heart infusion broth (Himedia laboratories, Mumbai, India) and all the tooth specimen which are further centrifuged to allow better penetration of broth into the dentinal tubules. ${ }^{19}$ The specimens were then autoclaved at $121^{\circ} \mathrm{C}$ for $15 \mathrm{~min}$ under $15 \mathrm{lbs}$ pressure and 
then the specimens were kept in an incubator at $37^{\circ} \mathrm{C}$ for 48 hours to assess the efficacy of the sterilization.

\subsection{Revival and Growth of the E. faecalis and specimen contamination}

The lyophilized powder of E. faecalis (MTCC 439) was purchased from Institute of Microbial Technology, Chandigarh, India and then these lyophilized bacterial strain was revived in anerobic conditions and by using sheep blood agar + Brain Heart Infusion agar plates as shown in Figure 1. Spectrophotometer as shown in Figure 2 was used to adjust the the optical density of the bacterial suspension to approximately $1.5 \times 10^{8}$ Colony Forming Units (CFU)/ ml (Concentration equivalent to 0.5 in the Mc Farland standard)

The glass test tube containing the sterile specimen and broth were opened inside laminar flow as shown in Figure 3 (Thermo Fisher Scientific Inc, Waltham , MA USA) and automated micropipette (Bio Gene micropipette, Biotech Inc, Chandigarh) was used to transfer $50 \mu 1$ of E.faecalis suspension into tubes and sterile cotton ball was used to close these tubes. The infected specimens were incubated at $37^{\circ} \mathrm{C}$ for seven days and every alternate day the specimens were transferred to fresh tubes containing $3 \mathrm{ml}$ of broth contaminated with $50 \mu 1$ of E. faecalis. ${ }^{20}$

\subsection{Irrigation protocol}

The irrigants tested were $0.1 \%$ Octenidine Dihydrochloride (Zotobac Solution,Pasumai Pharmacy, Coimbatore, Tamil $\mathrm{Nadu}$ ), 2\% chlorhexidine gluconate (Healthcare India Pvt. Ltd.,Raigad, Maharashtra) and 2\% chitosan (Everest Biotec, Bangalore).

The root specimens incubated for seven days will be randomly divided into 1 control group and 3 experimental group containing 18 teeth each.

Group 1 - 2\% chlorhexidene solution

Group $2-0.1 \%$ octenidine dihydrochloride solution

Group 3-2\% chitosan solution

Group 4- $0.9 \%$ normal saline (control group)

The root specimens incubated for seven days will be randomly divided into 1 control group and 3 experimental group containing 18 teeth each which were irrigated by respective irrigant till $3 \mathrm{~min}$ time interval with the use of a side venting 27 gauge endodontic irrigation needle and the tip of the needle was kept $1 \mathrm{~mm}$ short of working length using digital pressure.

\subsection{Microbial analysis}

A diamond disc was used to made horizontal notches at the junction of apical and middle third of the root and with the help of plier the apical segment was removed. Gates Glidden drills \#3 and \#4 were used to collect dental shavings at two depths $(200 \mu \mathrm{m}$ and $400 \mu \mathrm{m})$ respectively by using them in a circumferential technique in slow speed handpiece. ${ }^{19}$
$3 \mathrm{ml}$ of phosphate buffered solution contained in a test tube was used to collect the dental chips which were obtained by above procedure. Vigorous and active vortexing (Cyclo Mixer, Remi Laboratory Instruments, Mumbai, India) was performed till $5 \mathrm{~min}$ for suspension to be homogenized. The dental chips were then allowed to sediment for $5 \mathrm{~min}$ and the supernatant formed was used for microbial analysis. A sterile loop was used to remove $1 \mu 1$ of supernatant from the test tube and collected sample was inoculated on sheep blood agar plate using streaking method and incubated for 24 hours at $37^{\circ} \mathrm{C}$. For analysis the the number of colony forming units of $\mathrm{E}$ faecalis was calculated.

\subsection{Scanning electron microscope}

For SEM evaluation two teeth from each group was taken to determine the effect of various irrigation protocols. Grooves were made which are deep and longitudinal along the whole length of the buccal and lingual surfaces of the root specimen without perforating the canal before inoculation. Then specimens were irrigated with particular endodontic irrigant solution and immediately after the irrigation protocol the roots were split longitudinally using sterile Diamond disc used at slow speed handpiece. One half of each root was selected for examination under a scanning electron microscope (SEM) $\left(\mathrm{EVO}^{\circledR}\right.$ LS15, Carl Zeiss Microscopy GmbH, Goettingen, Germany) Ethyl alcohol (30-100\%) was used to dehydrate the coded samples by using the concentration in ascending order and the samples were then placed in a dessicator for atleast 24 hours , mounted on metallic stubs, gold sputtered and viewed under SEM and photographed at 1000x magnification.

\section{Statistical analysis}

The data were statistically analyzed with one way (ANOVA) and paired $t$ test. The ANOVA was used to check the difference in CFU count between groups $(\mathrm{p}<0.05)$. The paired t test was used to check for differences in CFU count for different irrigation protocol and at two depths $(\mathrm{p}<0.05)$. Statistical package for the social sciences (SPSS 16.0, SPSS Inc. Chicago, IL, USA) was used to perform the analysis.

\section{Results}

Groups 1-4 exerted antimicrobial activity. (table1) shows the mean CFU count of E. faecalis at two depths $(200 \mu \mathrm{m}$ and $400 \mu \mathrm{m}$ ) for four irrigation protocols with the result of $\mathrm{t}$ test. The number of $\mathrm{CFU}$ in all the experimental groups was significantly lower in comparision to control group.

Using one way ANOVA with multiple comparison, statistically non significant differences were found comparing group 1(OCT) with group 2(CHX) at 200 and $400 \mu \mathrm{m}$ depth proving OCT and CHX shows comparable results in reducing the CFU counts. Statistically significant differences were found $(\mathrm{p}=0.001)$ comparing group $1(\mathrm{OCT})$ 
with group 3(Chitosan) at 200 and $400 \mu \mathrm{m}$ depth proving chitosan is effective in reducing the CFU counts as compared to OCT. Statistically significant differences $(\mathrm{p}=0.001)$ were found comparing group $2(\mathrm{CHX})$ with group 3 (Chitosan) at 200 and $400 \mu \mathrm{m}$ depth proving chitosan is effective in reducing the CFU counts as compared to $\mathrm{CHX}$. Hence chitosan was most effective in reducing CFU counts of E. faecalis from the dentinal tubules.

The SEM evaluation shows the remaning bacterial colonies and debris accumulation present when the infected tooth was treated with the particular irrigant as shown in Figures 4, 5, 6 and 7.

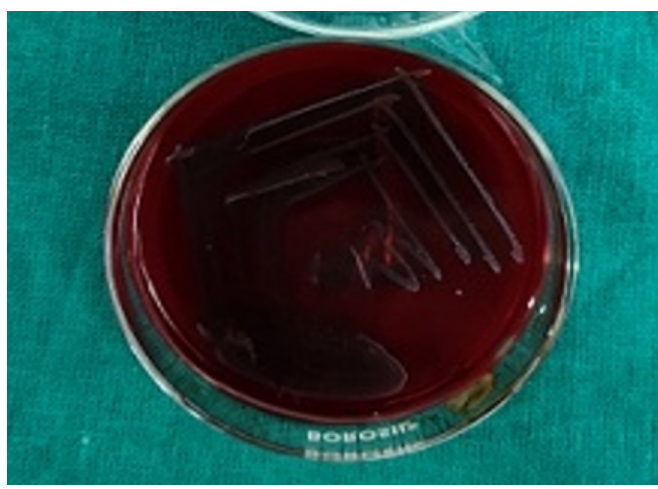

Fig. 1: E. faecalis colony on brain heart Infusion and sheep blood agar culture Plate

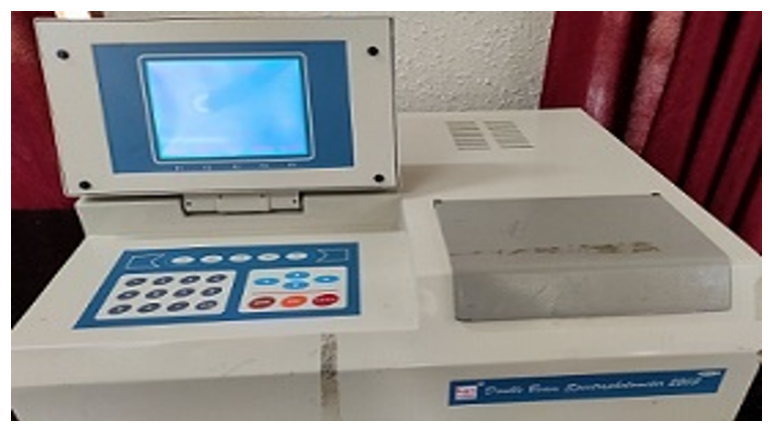

Fig. 2: Spectrophotometer

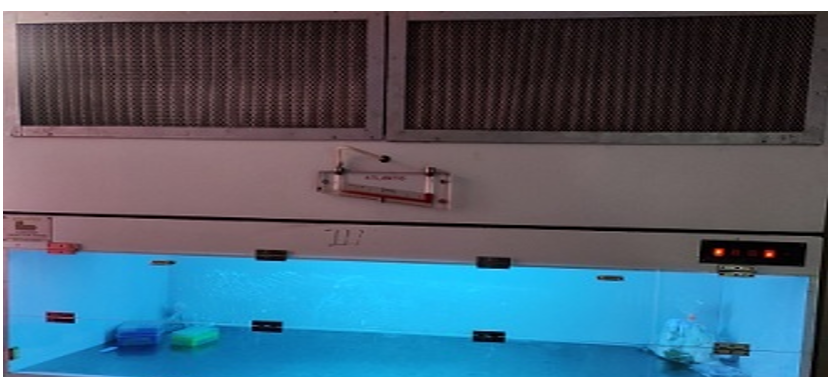

Fig. 3: Laminar flow

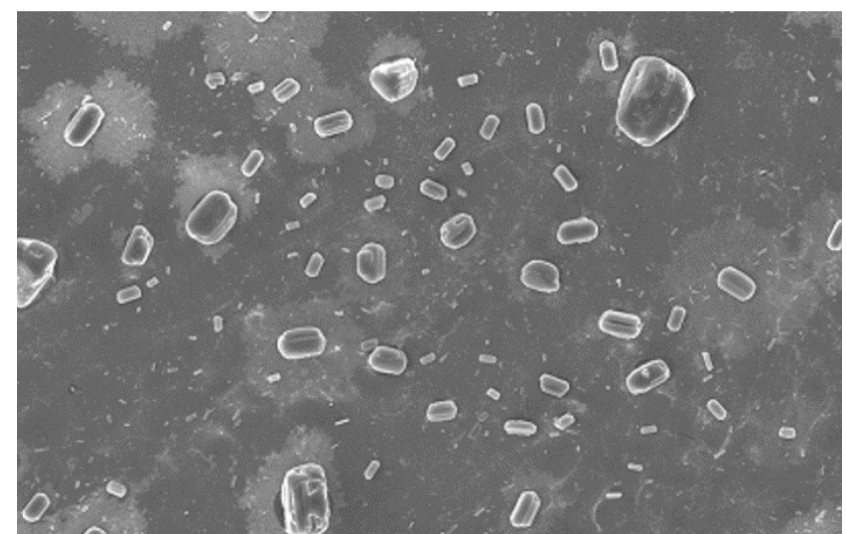

Fig. 4: Scanning electron micrograph of tooth section irrigated with OCT

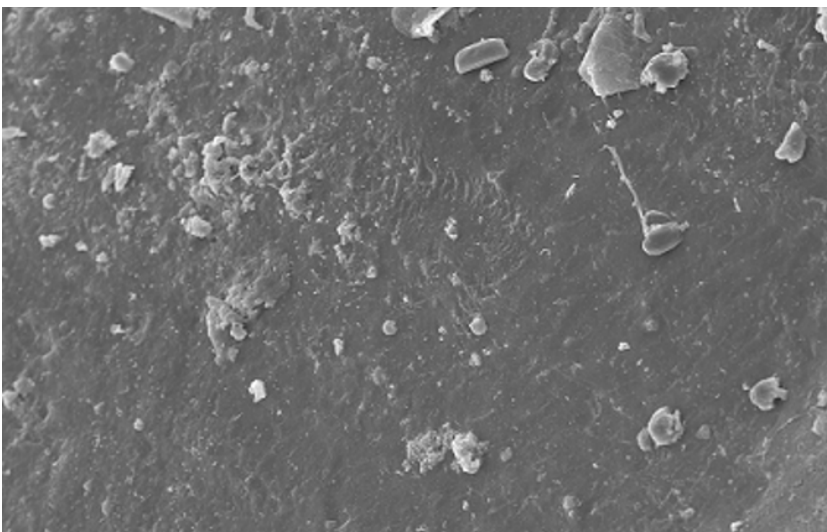

Fig. 5: Scanning electron micrograph of tooth section irrigated with CHX

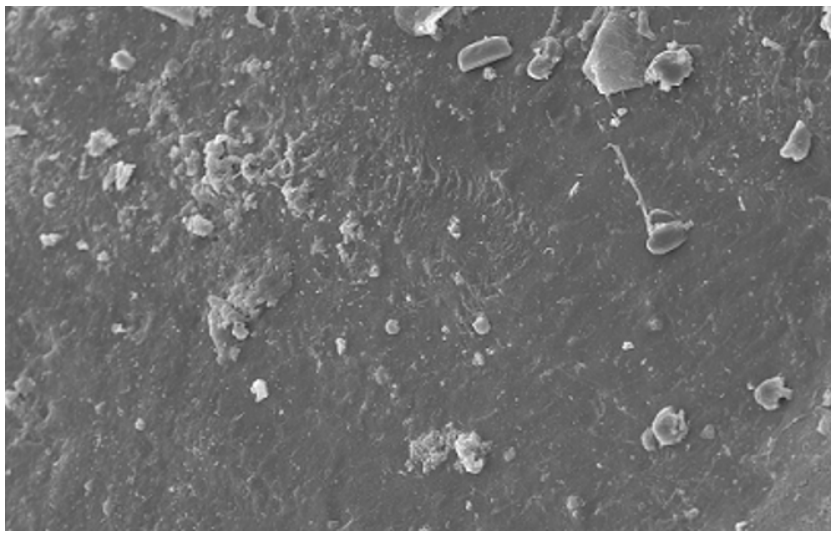

Fig. 6: Scanning electron micrograph of tooth section irrigated with chitosan 
Table 1: mean $( \pm \mathrm{SD})$ values of $\mathrm{CFU} / \mathrm{ml}$ of E.faecalis after tested irrigation solutions at 200 and $400 \mu \mathrm{m}$, with ANOVA and paired t test comparison

$\begin{array}{lccc}\text { Groups } & \text { Mean colony forming units } \pm \text { standard deviation } & \text { p value } \\ \text { Group 1 } & 200 \mu \mathrm{m} & 400 \mu \mathrm{m} & 0.085 \\ \text { Group 2 } & 60.83 \pm 1.72 & 62.50 \pm 1.22 & 0.220 \\ \text { Group 3 } & 51.33 \pm 1.72 & 52.16 \pm 1.16 & 0.128 \\ \text { Group 4 } & 51.33 \pm 0.51 & 52.50 \pm 1.51 & 0.541\end{array}$

One way ANOVA test for CFU between groups at $200 \mu \mathrm{m}$ and $400 \mu \mathrm{m}$ depth

\begin{tabular}{|c|c|c|c|}
\hline & Mean Difference & Std. Error & Sig. \\
\hline Gp I $(200 \mu)$ vs Gp II $(400 \mu)$ & $21.66667 *$ & .75732 & 0.001 \\
\hline Gp I $(200 \mu)$ vs GpIII $(200 \mu)$ & $23.16667 *$ & .7573 & 0.001 \\
\hline Gp I $(200 \mu)$ vs Gp IV $(200 \mu)$ & $-49.52381 *$ & .72977 & 0.001 \\
\hline Gp I $(200 \mu)$ vs Gp I $(400 \mu)$ & $-1.83333^{*}$ & .75732 & 0.020 \\
\hline Gp I $(200 \mu)$ vs GpII $(400 \mu)$ & $20.33333^{*}$ & .75732 & 0.001 \\
\hline Gp I $(200 \mu)$ vs GpIII $(400 \mu)$ & $20.50000^{*}$ & .75732 & 0.001 \\
\hline Gp I $(200 \mu)$ vs Gp IV $(400 \mu)$ & $-49.46667 *$ & .79428 & 0.001 \\
\hline Gp II $(200 \mu)$ vs Gp III $(200 \mu)$ & 1.50000 & .75732 & 0.055 \\
\hline Gp II $(200 \mu)$ vs Gp IV $(200 \mu)$ & $-71.19048^{*}$ & .72977 & 0.001 \\
\hline Gp II $(200 \mu)$ vs Gp I $(400 \mu)$ & $-23.50000 *$ & .75732 & 0.001 \\
\hline Gp II $(200 \mu)$ vs Gp II $(400 \mu)$ & -1.33333 & .75732 & 0.086 \\
\hline Gp II $(200 \mu)$ vs Gp III $(400 \mu)$ & -1.16667 & .75732 & 0.131 \\
\hline Gp II $(200 \mu)$ vs Gp IV $(400 \mu)$ & $-71.13333 *$ & .79428 & 0.001 \\
\hline Gp III $(200 \mu)$ vs Gp IV $(200 \mu)$ & $-72.69048 *$ & .72977 & 0.001 \\
\hline Gp III $(200 \mu)$ vs Gp I $(400 \mu)$ & $-25.00000 *$ & .75732 & 0.001 \\
\hline Gp III $(200 \mu)$ vs Gp II $(400 \mu)$ & $-2.83333^{*}$ & .75732 & 0.001 \\
\hline Gp III $(200 \mu) v s$ Gp III $(400 \mu)$ & $-2.66667 *$ & .75732 & 0.001 \\
\hline Gp III $(200 \mu)$ vs Gp IV $(400 \mu)$ & $-72.63333 *$ & .79428 & 0.001 \\
\hline Gp IV $(200 \mu)$ vs Gp I $(400 \mu)$ & $47.69048 *$ & .72977 & 0.001 \\
\hline Gp IV $(200 \mu)$ vs Gp II $(400 \mu)$ & $69.85714^{*}$ & .72977 & 0.001 \\
\hline Gp IV $(200 \mu)$ vs Gp III $(400 \mu)$ & $70.02381 *$ & .72977 & 0.001 \\
\hline Gp IV $(200 \mu)$ vs Gp IV $(400 \mu)$ & .05714 & .76806 & 0.941 \\
\hline Gp I $(400 \mu)$ vs Gp II $(400 \mu)$ & $22.16667 *$ & .75732 & 0.001 \\
\hline Gp I $(400 \mu)$ vs Gp III $(400 \mu)$ & $22.33333^{*}$ & .75732 & 0.001 \\
\hline Gp I $(400 \mu)$ vs Gp IV $(400 \mu)$ & $-47.63333 *$ & .79428 & 0.001 \\
\hline Gp II $(400 \mu)$ vs Gp III $(400 \mu)$ & .16667 & .75732 & 0.821 \\
\hline GpII $(400 \mu)$ vs Gp IV $(400 \mu)$ & $-69.80000^{*}$ & .79428 & 0.001 \\
\hline Gp III $(400 \mu)$ vs Gp IV $(400 \mu)$ & $-69.96667 *$ & .79428 & 0.001 \\
\hline
\end{tabular}

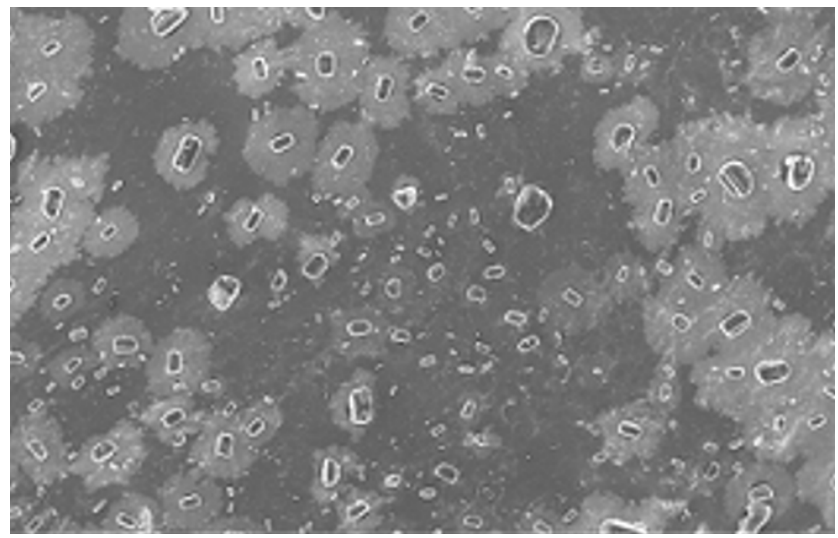

Fig. 7: Scanning electron micrograph of tooth section irrigated with normal saline

\section{Discussion}

The fundamental necessity for the success of endodontic treatment is by adequate shaping and thorough cleaning of the canal space which can be achieved by removal of any vital and necrotic pulp tissue, microorganisms and their by- products, along with removal of debris and smear layer ${ }^{21,22}$ However, the canal space shows a complex anatomy like oval extensions, fins, isthmuses and apical deltas which makes this goal difficult to achieve because these areas are difficult to access with the help of basic hand and rotary instruments. $^{23,24}$ studies showed that within oval canals only $40 \%$ of the apical passage wall area are often contacted by rotary instruments. hence, irrigation is crucial part of a endodontic treatment because it allows for cleaning 
beyond the reach of passage instruments.Haapasalo \& Ørstavik $(1987)^{25}$ developed an in vitro model which has been used to evaluate and access the disinfection of root canal passage within the dentinal tubules using endodontic medicaments. The model was then further modified by Lynne et.al. ${ }^{26}$ by incorporating quantitative chemical analysis of bacteria present within the dentine tubules which results in defining a percentage of reduction in CFU within the infected dentine before and after the application of intracanal medicaments and endodontic irrigants. The model has clear limitations because it doesn't reflect things in apical dentine, which is usually sclerotic (Paque et.al. 2006). E. faecalis, which is facultative anerobic in nature was chosen as a test organism because it can be easily grown on growth agar plates without special nutritional supplements and specific conditions and can be efficiently and rapidly colonizes the dentinal tubules (Ørstavik \& Haapasalo 1990). E. faecalis has been used extensively in endodontic research because it's been found to be present in $63 \%$ of teeth with post treatment disease (Hancock et.al. 2001). The adherence of E. faecalis to collagen fibres of dentin matrix was enhanced due to its capacity to breed within the deeper layers of dentine also as inside isthmuses and ramifications. Such residual bacteria probably evaded contact with passage irrigating solutions and medicaments at the required concentration and survived (Love 2001).

E. faecalis is a type of biological marker used in this study because of its clinical relevance in most of the root canal treatment cases, it has shown reported resistance to chemo- mechanical and intracanal medication procedures and for its prevalence in re treatment cases.[29.30] e .faecalis has shown proliferation and penetration deep itno the dentinal tubules as shown in various in- vitro infection studies. ${ }^{27}$ A seven day dentin contamination protocol as suggested by Haapasalo \& Ørstavik (modified) is used in the present study and in this model for broth efficiency and purity, the broth was changed on alternate days and it also helps to replenish the nutrient source. ${ }^{28}$

The nutritional conditions and the culture time taken for the growth of E. faecalis is directly associated with the depth of invasion into the dentinal tubules as shown by various in vitro studies. ${ }^{29}$ The Specimens which are infected for one day results in penetration of bacteria upto $300 \mu \mathrm{m}-400 \mu \mathrm{m}$ depth in a few canals when studied under light microscope and after three weeks of incubation with E.faecalis a moderate infection was usually seen upto $400 \mu \mathrm{m}-500 \mu \mathrm{m} .{ }^{28}$ The sampling procedure is quite sensitive and it was possible with the help of Gates Gidden drill to take sample from inside of canal lumen within the dentinal tubules at $200 \mu \mathrm{m}$ and $400 \mu \mathrm{m} .{ }^{30}$ Krithika Datta et al. had also performed similar sampling procedure in which the debris was collected in Eppendorf tubes contaning phosphate buffered saline $(1 \mathrm{ml})$ and 3 small glass beads. Active vortexing for atleast 5 min was performed to make homogenized suspension and then dentin chips were collected from supernatant solution to perform microbial analysis.

Octinisept (octenidine dihydrochloride) is an antiseptic for skin burns, wound disinfection and mouth rinses consisting of octenidine hydrochloride and phenoxyethanol. ${ }^{31}$ Octenidine hydrochloride belongs to the bipyridines carrying two cationic active centres per molecule and demonstrates broad spectrum antimicrobial effects covering both Gram-positive and Gram-negative bacteria, fungi and a number of other viral species (Sedlock \& Bailey 1985).

Octenidine has its mode of action by interfering with cell walls and membranes of bacteria/fungi. Phenoxyethanol, an ethanol derivate, is a preservative component in Octenisept which is has shown added advantage by improving the antibacterial activity of octenidine synergistically. Quite a few studies showed the efficacy of octenidine against dental plaque-associated bacteria, like Streptococcus mutans and Actinomyces viscosus like chlorhexidine digluconate (Slee \& O`Connor 1983, Decker et al. 2003). consistent with the manufacturer (Schu"lke \& Mayr, Norderstedt, Germany), the toxicity parameters of Octenisept are EC50 $>3200 \mathrm{mg} \mathrm{L}$ ) assessed by OECD 209-standards and LD 50 for rats $>45000 \mathrm{mg} \mathrm{kg}$ ). No carcinogenic or mutagenic effects are registered. Tandjung et al, demonstrated antimicrobial effectiveness of octenidine solution as endododntic irrigant against $\mathrm{E}$. faecalis in infected passage dentin model. ${ }^{32}$

2\% Chlorhexidine digluconate (CHX) has been suggested as a root canal irrigant due to its unique ability to bind to dentin easily, has shown its effectiveness as an antibacerial agent against E. faecalis and its prolonged association within the canal space in the root canal system which results ample time for its performance as an endodontic irrigant. ${ }^{33}$

Chitosan is cationically charged amino which shows its mechanism of action by combining with anionic components like $\mathrm{N}$-acetyl muramic acid, sialic acid, and neuramic acid which is present on the cell surface of bacteria and hence, suppresses the growth of bacteria by impairing the exchanges with medium, chelating transition metal ions, and inhibiting enzymes. Chitosan has shown antimicrobial action as when the positively charged NH3 + groups of glucosamine interacts with the negatively charged surface components of bacteria, results in extensive cell surface attraction, leakage of intracellular substances, and ultimately causing damage to vital bacterial activities. ${ }^{34,35}$

\section{Limitation}

It was an in vitro study, so accurate replication of clinical conditions are not feasible to achieve and difficulty was also present during assessing and retrieving the bacterial 
specimen from areas other than the main canal.

\section{Conclusion}

Under the limitation of present study, $2 \%$ chitosan was more effective in reducing CFU counts of E. faecalis than $0.1 \%$ OCT and $2 \% \mathrm{CHX}$ at 200 and $400 \mu \mathrm{m}$ depth when irrigated till 3 minutes.

The present study showed that the efficacy of chitosan is more as compared to other irrigant solution used in biological complex environment for further comparative studies, including common antimicrobial agents in endodontic.

\section{Source of Funding}

No financial support was received for the work within this manuscript.

\section{Conflict of Interest}

The authors declare they have no conflict of interest.

\section{References}

1. Burleson A, Nusstein J, Reader AL, Beck M. The In Vivo Evaluation of Hand/Rotary/Ultrasound Instrumentation in Necrotic, Human Mandibular Molars. J Endod. 2007;33(7):782-7. d01:10.1016/].joen.2007.04.015.

2. Mayer BE, Peters OA, Barbakow F. Effects of rotary instruments and ultrasonic irrigation on debris and smear layer scores: a scanning electron microscopic study. Int Endod J. 2002;35(7):5829. $101: 10.1046 / \mathrm{j} .1365-2591.2002 .00502 . \mathrm{x}$

3. Khademi A, Yazdizadeh M, Feizianfard M. Determination of the Minimum Instrumentation Size for Penetration of Irrigants to the Apical Third of Root Canal Systems. J Endod. 2006;32(5):417-20. do1:10.1016/1.10en.2005.11.008

4. Lee SJ, Wu MK, Wesselink PR. The effectiveness of syringe irrigation and ultrasonics to remove debris from simulated irregularities within prepared root canal walls. Int Endod J. 2004;37(10):672-8. doi:10.1111/.1365-2591.2004.00848.x.

5. Guneser M, Bilge M, Unverdi A. Antibacterial effect of chlorhexidinecetrimide combination, $<\mathrm{i}>$ Salvia officinalis $</ \mathrm{i}>$ plant extract and octenidine in comparison with conventional endodontic irrigants. Dent Mater J. 2016;35:736-41. d01:10.4012/dm].2015-159.

6. Cherian B, Parasmullgehlot. Mysore Krishnaswamy Manjunath Comparision of the antimicrobial efficacy of Octenidine dihydrochloride and chlorhexidiene with and without Passive Ultrasonic Irrigation -An in vitro study. $J$ Clin Diagn Res. 2016;10(6):ZC71-7.

7. Ertan T, Meriç Y, Tunca J. Comparative Evaluation of Microleakage for Different Root Canal Sealers and Irrigation Solutions. J Clin Anal Med. 2010;1(2):9-14. do1:10.4328/jcam.52

8. Kumar G, Uppin V, Shenoy A. Comparison of Antibacterial Effects of Various Root Canal Irrigants on Enterococcus faecalis. World J Dent. 2011;2(3):211-5. doi:10.5005/jp-journals-10015-1085.

9. Narayanan L, Vaishnavi C. Endodontic microbiology. J Conserv Dent.

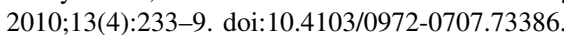

10. Sedlock DM, Bailey DM. Microbicidal activity of octenidine hydrochloride, a new alkanediylbis[pyridine] germicidal agent. Antimicrob Agents Chemother. 1985;28(6):786-90. doi:10س28/aac.28.6.786

11. Slee AM, O'Connor JR. In vitro antiplaque activity of octenidine dihydrochloride (WIN 41464-2) against preformed plaques of selected oral plaque-forming microorganisms. Antimicrob Agents Chemoth.

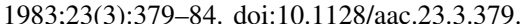

12. Shern RJ, Monell-Torrens E, Kingman A. Effect of Two Recently Developed Antiseptics on Dental Plaque and Caries in Rats. Caries Res. 1985;19(5):458-65. 100:10/159/000260882.

13. Tirali RE, Bodur H, Sipahi B, Sungurtekin E. Evaluation of the antimicrobial activities of chlorhexidine gluconate, sodium hypochlorite and octenidine hydrochloride in vitro. Aust Endod J. 2013;39:15-18.

14. Ercan E, Ozekinci T, Atakul F, Gul K. Antibacterial Activity of 2\% Chlorhexidine Gluconate and 5.25\% Sodium Hypochlorite in Infected Root Canal: In Vivo Study. J Endod. 2004;30(2):84-7. 10:-101097100004770-200402000-00005.

15. Kumar ABV, Varadaraj MC, Gowda LR, Tharanathan RN Characterization of chito-oligosaccharides prepared by chitosanolysis with the aid of papain and Pronase, and their bactericidal action against Bacillus cereus and Escherichia coli. Biochemical $J$. 2005;391(2):167-75. doi:10.1042/bj20050093.

16. Felt O, Carrel A, Baehni P, Buri P, Gurny R. Chitosan as Tear Substitute: A Wetting Agent Endowed with Antimicrobial Efficacy. J Ocul Pharmacol Ther . 2000;16(3):261-70.

17. Otuka ES, Pedrazzani ES, Pioto MP. The use of papain in plantar ulcers. Rev Bras Enferm. 1996;49:207-14.

18. Martins MD, Fernandes KP, Motta LJ, Santos EM, Pavesi VC, Bussadori SK, et al. Biocompatibility analysis of chemomechanical caries removal material Papacarie on cultured fibroblasts and subcutaneous tissue. J Dent Child (Chic). 2009;76(2):123-9.

19. Crd S, Oliveira M, Motta ES, Gsd A, Varanda LL, Md P, et al. Caldeira-de-Araujo A. Genotoxic and cytotoxic safety evaluation of papain (Carica papaya L.) using in vitro assays. J Biomed Biotechnol. 2010;2010:197898.

20. Gomes BPFA, Ferraz CCR, E VM, Berber VB, Teixeira FB, Souza-Filho FJ, et al. In vitro antimicrobial activity of several concentrations of sodium hypochlorite and chlorhexidine gluconate in the elimination of Enterococcus faecalis. Int Endod $J$. 2001;34(6):424-8. do1:10.1046/].1365-2591.2001.00410.x.

21. Berber VB, Gomes BPFA, Sena NT, Vianna ME, Ferraz CCR, Zaia AA, et al. Efficacy of various concentrations of $\mathrm{NaOCl}$ and instrumentation techniques in reducing Enterococcus faecalis within root canals and dentinal tubules. Int Endod J. 2006;39(1):10-7. doi:10.1111/.1365-2591.2005.01038.x

22. Bhuva B, Patel S, Wilson R, Niazi S, Beighton D, Mannocci $\mathrm{F}$, et al. The effectiveness of passive ultrasonic irrigation on intraradicularEnterococcus faecalisbiofilms in extracted single-rooted human teeth. Int Endod J. 2010;43(3):241-50. ब01:10.1111/].1365 एक्य.200पण $6 / 2 x$.

23. Haapasalo M, Endal U, Zandi H, Coil JM. Eradication of endodontic infection by instrumentation and irrigation solutions. Endod Topics. 2005;10(1):77-102. doi:10.1111/1.1601-1546.2005.00135.x.

24. Sabins RA, Johnson JD, Hellstein JW. A Comparison of the Cleaning Efficacy of Short-Term Sonic and Ultrasonic Passive Irrigation after Hand Instrumentation in Molar Root Canals. $J$ Endod. 2003;29(10):674-8. 101:0109700004 -700-2003 10000-00016.

25. Haapasalo M, Ørstavik D. In vitro Infection and of Dentinal Tubules. $J$ Dent Res. 1987;66(8):1375-9. 10ن:0. 177100220345870660081801.

26. Lynne R, Liewehr FR, West L, Patton W, Buxton T, McPherson J, et al In Vitro Antimicrobial Activity of Various Medication Preparations on E. faecalis in Root Canal Dentin. J Endod. 2003;29(3):187-90. 101:10-109700004 $170-200303000-00006$.

27. Gründling GL, Zechin JG, Jardim WM, de Oliveira SD, de Figueiredo JAP. Effect of Ultrasonics on Enterococcus faecalis Biofilm in a Bovine Tooth Model. J Endod. 2011;37(8):1128-33. doi:10.1016/1.joen.2011.05.006.

28. Haapasalo M, Endal U, Zandi H, Coil JM. Eradication of endodontic infection by instrumentation and irrigation solutions. Endod Topics. 2005;10(1):77-102. do1:10.1111/1.1601-1546.2005.00135.X.

29. Gomes BPFA, Ferraz CCR, E VM, Berber VB, Teixeira FB, SouzaFilho FJ, et al. In vitro antimicrobial activity of several concentrations of sodium hypochlorite and chlorhexidine gluconate in the elimination of Enterococcus faecalis. Int Endod J. 2001;34(6):424-48. 


\section{do1:10.1046/].1365-2591.2001.00410.x}

30. Basrani B, Santos JM, Tjäderhane L, Grad H, Gorduysus O, Huang J, et al. Substantive antimicrobial activity in chlorhexidine-treated human root dentin. Oral Surg, Oral Med, Oral Pathol, Oral Radiol, Endodontol. 2002;94:240-5.

31. Tirali RE, Turan Y, Akal N, Karahan ZC. In vitro antimicrobial activity of several concentrations of $\mathrm{NaOCl}$ and Octenisept in elimination of endodontic pathogens. Oral Surg, Oral Med, Oral Pathol, Oral Radiol, Endodontol. 2009;108:e117-20. doi:10.1016/j.tripleo.2009.07.012

32. Tandjung L, Waltimo T, Hauser I, Heide P, Decker EM, Weiger R, et al. Octenidine in root canal and dentine disinfection ex vivo. Int Endod J. 2007;40(11):845-51. doi:10.1111/1.1365-2591.2007.01279.x

33. White RR, Hays GL, Janer LR. Residual antimicrobial activity after canal irrigation with chlorhexidine. J Endod. 1997;23(4):229-31. do1:10.1016/s0099-2399(9)80052-0.

34. Ballal NV, Kundabala M, Bhat KS, Acharya S, Ballal M, Kumar R, et al. Susceptibility ofCandida albicansandEnterococcus faecalisto Chitosan, Chlorhexidine gluconate and their combinationin vitro. Aust Endod J. 2009;35(1):29-33. doi:10.1111/.1747-4477.2008.00126.x.
35. Raafat D, Sahl HG. Chitosan and its antimicrobial potential - a critical literature survey. Microbial Biotechnol. 2009;2(2):186-201. 0o1:10.111/].1751-7915.2008.00080.x.

\section{Author biography}

Akanksha Joon, Post Graduate Student

Ambica Khetarpal, Reader

Sanju Dahiya, Post Graduate Student

Cite this article: Joon A, Khetarpal A, Dahiya S. Comparitive evaluation of antimicrobial efficacy of $0.1 \%$ octenidine dihydrochloride, $2 \%$ chlorhexidine and $2 \%$ chitosan against E.faecalis within the dentinal tubules. IP Indian J Conserv Endod 2020;5(4):192-199. 